\title{
SMOKE-POINT PROPERTIES OF NONBUOYANT ROUND LAMINAR JET DIFFUSION FLAMES
}

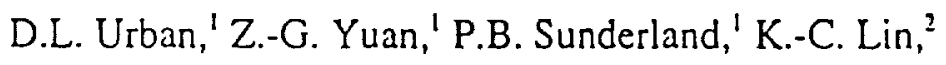 \\ Z. Dai ${ }^{2}$ and G.M. Faeth ${ }^{2}$ \\ 'NASA Glenn Research Center \\ Cleveland, OH 44135, USA \\ ${ }^{2}$ University of Michigan \\ Ann Arbor, MI 48109, USA
}

Submitted to:

$28^{\text {th }}$ International Symposium on Combustion

Colloquium Topic: $\quad$ Laminar Flames: R.P. Lindstedt and T. Takeno

Authors Preference: Oral Presentation

Date Submitted: $\quad$ December 1999

Corresponding Author: G. M. Faeth

The University of Michigan

3000 FXB Building

Ann Arbor, MI 48109-2140, USA

Tel: 734-764-7202

Fax: 734-936-0106

Eml: gmfaeth@umich.edu

Paper Length:

$\begin{aligned} 4069 \text { text words } \times 1 & = & 4069 \text { words } \\ 1 \text { equation } \times 21 & = & 21 \text { words } \\ 1 \text { nomenclature } & = & 119 \text { words } \\ 5 \text { figures } \times 200 & = & 1000 \text { words } \\ 0 \text { tables } \times 200 & = & \frac{0 \text { words }}{5209 \text { words }}\end{aligned}$




\title{
SMOKE-POINT PROPERTIES OF NONBUOYANT ROUND LAMINAR JET DIFFUSION FLAMES
}

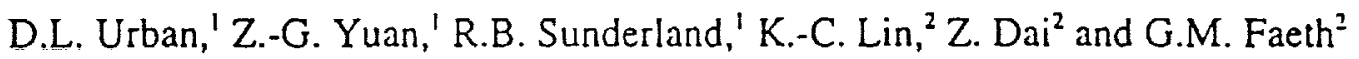 \\ 'NASA Glenn Research Center \\ Cleveland, OH 44135, USA \\ ${ }^{2}$ University of Michigan \\ Ann Arbor, MI 48109, USA
}

The laminar smoke-point properties of nonbuoyant round laminar jet diffusion flames were studied emphasizing results from long duration (100-230s) experiments at microgravity carried out on orbit in the Space Shuttle Columbia. Experimental conditions included ethylene-and propane-fueled flames burning in still air at an ambient temperature of $300 \mathrm{~K}$, initial jet exit diameters of 1.6 and $2.7 \mathrm{~mm}$, jet exit velocities of $170-1630 \mathrm{~mm} / \mathrm{s}$, jet exit Reynolds numbers of 46-172, characteristic flame residence times of 40-302 ms, and luminous flame lengths of $15-63 \mathrm{~mm}$. The onset of laminar smoke-point conditions involved two flame configurations: closed-tip flames with first soot emissions along the flame axis and open-tip flames with first soot emissions from an annular ring about the flame axis. Open-tip flames were observed at large characteristic flame residence times with the onset of soot emissions associated with radiative quenching near the flame tip; nevertheless, unified correlations of laminar smoke-point properties were obtained that included both flame configurations. Flame lengths at laminar smoke-point conditions were well-correlated in terms of a corrected fuel flow rate suggested by a simplified analysis of flame shape. The present steady and nonbuoyant flames emitted soot more readily than earlier tests of nonbuoyant flames at microgravity using ground-based facilities and of buoyant flames at normal gravity due to reduced effects of unsteadiness, flame disturbances and buoyant motion. For example, laminar smoke-point flame lengths from ground-based microgravity measurements were up to 2.3 times longer and from buoyant flame measurements were up to 6.4 times longer than the present measurements at comparable conditions. Finally, present laminar smoke-point flame lengths were roughly inversely proportional to pressure, which is a somewhat slower variation than observed during earlier tests both at microgravity using ground-based facilities and at normal gravity. 


\section{Introduction}

The laminar smoke-point properties of jet diffusion flames (e.g., the luminous flame length, fuel flow rate, characteristic residence time, etc., at the onset of soot emissions) are useful observable soot properties of non-premixed flames. For example, these measures provide a means to rate several aspects of flame sooting properties: the relative propensity of various fuels to produce soot in flames $[1-4]$; the relative effects of fuel structure, fuel dilution, flame temperature and flame pressure on the soot emission properties of flames [514]; the relative levels of continuum radiation from soot in flames [15-17]; and effects of the intrusion of gravity (buoyancy) on emissions of soot from flames [18-26]. Laminar smokepoint properties generally are measured using buoyant round laminar jet diffusion flames, surrounded by co-flowing air in order to prevent pulsations characteristic of buoyant jet diffusion flames in still environments. Laminar smoke-point properties found using this configuration are relatively independent of burner diameter and co-flow velocities, tending to enhance their value as global measures of soot properties $[9,10]$. Recent studies, however, suggest that the laminar smoke-point properties of buoyant and nonbuoyant laminar jet diffusion flames are fundamentally different [19-26]. Thus, the overall objective of the present investigation was to measure the laminar smoke-point properties of nonbuoyant flames, due to the relevance of nonbuoyant flames to most practical industrial processes where effects of buoyancy are small. 
The potential differences between the laminar smoke properties of buoyant and nonbuoyant flames can be attributed mainly to the different hydrodynamic properties of these flames [24-27]. In particular, soot particles are too large to diffuse like gas molecules so that they are convected by gas velocities aside from minor effects of thermophoresis [24]. As a result, flow acceleration due to gravitational forces in buoyant round laminar jet diffusion flames implies that soot mainly nucleates near the flame sheet and then is drawn toward fuelrich conditions nearer the flame axis, promoting soot growth for an extended residence time, before the soot finally crosses the flame sheet within an annular soot layer near the flame tip to reach soot oxidation conditions. This type of soot path, denoted soot-formation flame conditions by Kang et al. [27], tends to promote soot growth and inhibit soot oxidation, enhancing the tendency of the flame to emit soot. On the other hand, flow deceleration in nonbuoyant round laminar jet diffusion flames implies that soot mainly nucleates in the cool core of the flame at fuel-rich conditions and then is drawn directly toward and through the flame sheet, so that soot tends to leave the flame over a relatively extended region. This type of soot path, denoted soot-formation-oxidation conditions by Kang et al. [27], tends to inhibit soot growth and enhance soot oxidation compared to buoyant flames having similar characteristic residence times, reducing the tendency of the flame to emit soot. Thus, the soot nucleation, growth, and oxidation envircnments of buoyant and nonbuoyant laminar jet diffusion flames are quite different, providing significant potential for different laminar smoke-point properties as well. 
Several studies of the laminar smoke-point properties of nonbuoyant laminar jet diffusion flames have been reported, motivated by the potential effects of buoyancy on laminar smoke-point properties, see Refs. 18-25 and references cited therein. Most of these studies used ground-based microgravity facilities to observe nonbuoyant flames, finding that laminar smoke-point flame lengths were significantly smaller and laminar smoke-point characteristic residence times were significantly larger for nonbuoyant than buoyant flames. These differences generally have been attributed to the different soot paths in buoyant and nonbuoyant flames that were just discussed as well as increased effects of radiative quenching in nonbuoyant flames due to their increased characteristic residence times compared to buoyant flames. A concern about these results, however, is that limited testing using space-based microgravity facilities yielded significantly different results than observed using ground-based microgravity facilities [25]. Thus, the objective of the present study was to more completely access these differences by measuring laminar smoke-point properties during long-term experiments (100-230s) at small g-jitter conditions carried out on orbit in the Space Shuttle Columbia (flights STS-83 and 94). The scope of the study was limited to round ethylene-and propane-fueled laminar jet diffusion flames burning in still and slightly vitiated air at pressures of $35-130 \mathrm{kPa}$.

\section{Experimental Methods}

Experimental methods will be described only briefly, see Urban et al. [25] for details about the apparatus and instrumentation and Lin et al. [28] for a tabulation of test conditions. 
The laminar jet diffusion flames were stabilized at the exit of round fuel nozzles located along the axis of a windowed chamber having a diameter and length of 400 and $740 \mathrm{~mm}$. The chamber was filled with oxygen/nitrogen mixtures to provide the nominal composition of dry air ( $21 \pm 1 \%$ oxygen by volume). The properties of the gas surrounding the flames varied slightly over the present relatively long test times because the test chamber was closed. The greatest change involved the gas composition but even this change was modest with maximum oxygen consumptions never exceeding $2 \%$ by volume during any test. These conditions were maintained by periodically venting the chamber to space and adding fresh dry air in the period between tests.

Stainless steel fuel nozzles having inside diameters of 1.6 and $2.7 \mathrm{~mm}$, lengths of 148 $\mathrm{mm}$ and inlet flow straighteners yielded nonswirling fully developed laminar flow at the jet exit. The test fuels were stored in cylinders and delivered to the nozzles through solenoid valves and a mass flow rate controller and sensor. The flames were ignited with a hot wire coil that was retracted from the nozzle exit once the flame was stabilized.

Monitoring measurements included the fuel flow rate, the fuel inlet temperature, the chamber pressure, and the chamber gas temperature $[25,28]$. The flames were observed using a color CCD video camera (Hitachi, Model KP-C553) with a $125 \times 164 \mathrm{~mm}$ field of view and a $25 \mathrm{~mm}$ depth of field centered on the flame axis. Flame images were recorded at a rate of $30 \mathrm{images} / \mathrm{s}$ and could be measured with a spatial resolution better than $0.3 \mathrm{~mm}$. Initial 
fuel flow rates were set in excess of laminar smoke-point flow rates and could be adjusted up to $\pm 30 \%$ in $5 \%$ steps, to achieve the desired final conditions near (within $5 \%$ ) but generally smaller than laminar smoke-point fuel flow rates. There were 3 tests that were exceptions where initial excessively large fuel flow rates prevented finally reaching flame lengths shorter than laminar smoke-point conditions, as noted by Lin et al. [28].

A total of 21 flames were observed, yielding the following ranges of test properties: ethylene- and propane-fueled flames, ambient air temperatures and pressures of $300 \mathrm{~K}$ and 35-130 kPa, jet exit velocities and Reynolds numbers of $170-1630 \mathrm{~mm} / \mathrm{s}$ and $46-172$, characteristic residence times, $t_{\mathrm{ch}}$, of 40-302 ms, and luminous flame lengths, $\mathrm{L}$, of 15-63 $\mathrm{mm}$.

\section{Results and Discussion}

\section{Flow Visualization}

Typical of many past observations of nonbuoyant round laminar jet diffusion flames

$[18-22,24,25,28]$, the present flames could be grouped into closed-tip and open-tip configurations. The difference between these two configurations was particularly noticeable in the vicinity of the laminar smoke-point as illustrated by the photographs of Fig. 1. These photographs show the flame appearance as the fuel flow rate is increased in the transition region where the laminar smoke-point is approached and exceeded for ethylene-fueled 
flames having $1.6 \mathrm{~mm}$ jet exit diameters. The upper series of photographs show the behavior of larger characteristic residence time flames (larger than $80 \mathrm{~ms}$ ) where the flame tips were blunt (open-tip) throughout the transition to soot emitting conditions and the first emission of soot was associated with an annular region surrounding the flame axis and having a diameter comparable to the maximum flame diameter. The lower series of photographs show the behavior of small characteristic residence time flames (smaller than $80 \mathrm{~ms}$ ) where the flame tips were rounded (closed-tip) and the first emission of soot was associated with the flame axis. Even these flames, however, eventually exhibit open-tip behavior as fuel flow rates increased beyond the laminar smoke-point condition. Thus, tip opening generally is closely associated with laminar smoke-point conditions for nonbuoyant flames, which has also been observed by several other investigators, see Refs. 18-22 and references cited therein.

Measurements of soot concentrations in the present flames using deconvoluted laser extinction show that soot is contained within a narrow annular ring and that no soot is present at the flame axis for open-tip conditions [25]. Corresponding soot temperatures using deconvoluted multiline emission measurements show that soot temperatures progressively decrease with increasing streamwise distances in open-tip flames and reach values of roughly $1000 \mathrm{~K}$ near the flame tip [25]. Low reaction rates at such conditions are consistent with quenching of soot oxidation, allowing soot to escape from the flame tip. The main mechanism causing this progressive reduction of temperature is continuum radiation from 
soot. This radiative heat loss becomes more significant with increasing streamwise distance due to the progressive reduction of flow velocities which involves a corresponding reduction of transport and thus reaction rates at the flame sheet. The corresponding reduced chemical energy release rates, combined with progressively increasing radiative heat losses due to increasing soot concentrations, provides ample potential for quenching and thus tip-opening and corresponding emissions of soot. In contrast, buoyant diffusion flames have progressively increasing velocities and thus increasing transport rates with increasing streamwise distance, due to effects of buoyancy, so that soot emissions occur due to rapid mixing and insufficient residence time to complete soot oxidation rather than by radiative quenching [25]. Finally, this latter condition is approached by nonbuoyant flames at short residence times where effects of radiative quenching are reduced, tending toward the closedtip laminar smoke-point behavior illustrated in the lower photograph of Fig. 1.

\section{Luminous Flame Lengths}

Similar to the observations of luminous flame lengths at the smoke-points of buoyant round laminar jet diffusion flames due to Schug et al. [5], the present luminous flame lengths at the smoke-points of nonbuoyant round laminar jet diffusion flames were closely associated with the fuel flow rate as suggested by the simplified analysis of Lin et al. [2S]. This behavior is illustrated in Fig. 2 where present measurements of laminar smoke-point luminous flame lengths are plotted as a function of the corrected fuel flow rate based on the 
results of the simplified flame shape theory for nonbuoyant laminar jet diffusion flames of Ref. 28. The open symbols on this plot denote the three test conditions where soot emitting flames just beyond the laminar smoke-point conditions were measured; nevertheless, these measurements are very similar to the remaining results which were at the laminar smokepoint but were not emitting soot. The one data point remote from the rest was at the lowest pressure tested, $35 \mathrm{kPa}$, where luminous flame lengths and the onset of soot emitting conditions were more difficult to observe due to relatively small maximum soot concentrations (less than I ppm based on multiline emission measurements). Except for the one outlier, the correlation between luminous flame lengths and corrected fuel mass flow rates at laminar smoke-point conditions is seen to be quite good; therefore, laminar smokepoint properties will be represented by luminous flame lengths alone to simplify the comparison between present measurements and the earlier findings of Refs. 5,16 and 24 .

An explanation of the luminous flame length behavior observed in Fig. 2 can be obtained from the flame shape correlations of Lin et al. [28] for nonbuoyant round laminar jet diffusion flames in still air. These results are based on a simplified analysis due to Spalding [29] for this flame configuration. Ignoring small effects of the virtual origin, this correlation can be written to yield the luminous flame length as a function of the corrected fuel flow rate parameter used in Fig. 2, as follows:

$$
L=\left(3 C_{1} / 32\right)\left(4 \dot{\mathrm{m} \mathrm{Sc}} /\left(\mathrm{Z}_{\mathrm{st}} \mu \pi\right)\right)
$$


Following Ref. 28, a simple correlation of Eq. (1) was fitted to the measurements of flames in air environments using values of $\mathrm{Sc}$ and $\mu$ for air at roughly the average of the adiabatic flame temperature and the ambient temperature (the values used are summarized on the plot). The correlation shown in the figure is for $C_{f} \approx 1$ for flames at the laminar smoke-point from Lin et al. [28], in contrast to $C_{f} \approx 0.5$ for soot-free blue flames from Sunderland et al. [30]. The longer soot-containing flames are consistent with luminosity due to the presence of soot at fuel-lean conditions for flames at the transition to soot emissions [28]. Finally, it is evident that Eq. (1) provides a surprisingly good correlation between luminous flame lengths and the corrected mass flow rate for present observations of nonbuoyant round laminar jet diffusion flames in spite of the approximate nature of the Spalding [29] analysis.

\section{Laminar Smoke Points}

In view of the different mechanisms leading to the onset of soot emissions for buoyant and nonbuoyant laminar jet diffusion flames, it is not surprising that they have substantially different laminar smoke-point properties. This behavior is illustrated in Figs. 3 and 4 by plots of laminar smoke-point flame lengths for ethylene- and propane-fueled flames. Measurements illustrated in the figures include results for nonbuoyant flames having jet exit diameters of 1.6 and $2.7 \mathrm{~mm}$ from the present space-based experiments, results for nonbuoyant flames having jet exit diameters of $1.6,2.7$ and $5.6 \mathrm{~mm}$ from Sunderland et al. 
[24] using ground-based microgravity facilities and results for buoyant flames having jet exit diameters of $10.0 \mathrm{~mm}$ from Schug et al. [5] and $14.3 \mathrm{~mm}$ from Sivathanu and Faeth [16].

There are several interesting features about the measurements illustrated in Figs. 3 and 4. First of all, an obvious feature of these results is that the present laminar smoke-point flame lengths of the nonbuoyant flames are significantly smaller that those of the buoyant flames. For example, the laminar smoke-point flame lengths of the buoyant flames are up to 6.4 times larger than the present nonbuoyant flames at comparable conditions. This behavior comes about because the present nonbuoyant flames have much larger characteristic residence times (up to $300 \mathrm{~ms}$ [28]) than the buoyant flames (only up to $50 \mathrm{~ms}$ [24]) due to buoyancy-induced motion in spite of the greater length of the buoyant flames. This provides greater potential for radiative heat losses for the nonbuoyant flames, leading to the radiative quenching mechanism of soot emissions discussed in connection with Fig. I concerning tip opening.

An important feature of the laminar smoke-point flame lengths illustrated in Figs. 3 and 4 for the present nonbuoyant flames is that they are significantly smaller than results for nonbuoyant flames using ground-based microgravity facilities. For example, the laminar smoke-point flame lengths of the nonbuoyant flames using ground-based microgravity facilities are up to 2.3 times longer than the preseni nonbuoyant flames at comparable conditions. This behavior is caused by the closer approach to steady and nonbuoyant flame properties of the long-term space-based experiments compared to the relatively unsteady and 
disturbed microgravity environment of ground-based microgravity facilities. For example, flow velocities are very small near the flame tip of nonbuoyant laminar jet diffusion flames [24] and can be disturbed by small levels of g-jitter with the resulting enhanced mixing deferring radiative quenching. This behavior is exacerbated by the relatively slow development of nonbuoyant flames for the jet exit diameters considered during the groundbased microgravity tests [25]. Further evidence of enhanced mixing for the ground-based microgravity tests compared to the space-based tests is provided by the observations of generally shorter luminous flame lengths at comparable conditions for the ground-based results, e.g., 30\% shorter as discussed by Lin et al. [28].

Another difference between the laminar smoke-point properties of nonbuoyant flames using ground- and space-based microgravity facilities involves the pressure dependence. In particular, the present long-term microgravity experiments yield laminar smoke-point flame lengths that are roughly inversely proportional to pressure. In contrast, the more disturbed microgravity environment of the ground-based facilities yields laminar smoke-point flame lengths that are inversely proportional to pressure to the 1.4 power. This latter behavior is even a stronger pressure variation than observed for buoyant flames where Flower and Bowman [11-14] report laminar smoke-point flame lengths inversely proportional to pressure to the 1.3 power. Differences of the pressure dependence of these magnitudes are of interest for gaining a better understanding of soot formation in diffusion names, see Glassman [10], 
which highlights the importance of achieving truly steady and nonbuoyant diffusion flame conditions for reliable experimental results.

Other properties of the laminar smoke-point flame lengths plotted in Figs. 3 and 4 are qualitatively similar for nonbuoyant space-based flames, nonbuoyant ground-based flames and buoyant flames. For example, effects of jet exit diameter on laminar smoke-point flame lengths are small in all three cases, which agrees with the well-known behavior of buoyant flames, see Glassman $[9,10]$. This behavior is expected for buoyant flames because both their flame heights and characteristic residence times are independent of jet exit diameter, with the latter being largely a function of flame height [16]. This behavior is not expected for nonbuoyant flames, however, because while their flame lengths are independent of jet exit diameter as discussed in connection with Fig. 2, their characteristic residence times decrease with decreasing jet exit diameter [24] which should lead to corresponding increases of laminar smoke-point flame lengths. Such increases are not observed and explaining this behavior merits further study. Finally, the laminar smoke-point flame lengths of ethylenefueled flames are smaller than those of propane-fueled flames for all three flame conditions considered in Figs. 3 and 4. This behavior agrees with past observations of the greater propensity to soot of ethylene-fueled compared to propane-fueled laminar jet diffusion flames $[5,15,16]$. 


\section{Conclusions}

The smoke-point properties of nonbuoyant round laminar jet diffusion flames were observed during long term (100-230s) experiments at microgravity using space-based facilities. Measurements included ethylene- and propane-fueled flames burning in still air at an ambient temperature of $300 \mathrm{~K}$, pressures of $35-130 \mathrm{kPa}$, jet exit diameters of 1.6 and 2.7 $\mathrm{mm}$, jet exit velocities of $170-1630 \mathrm{~mm} / \mathrm{s}$, jet exit Reynolds numbers of 46-172, characteristic flame residence times of 40-302 ms and luminous flame lengths of $15-63 \mathrm{~mm}$. The major conclusions of the study are as follows:

1. The onset of laminar smoke-point conditions involved either a closed-tip configuration with first soot emissions along the flame axis or an open-tip configuration with first soot emissions from an annular ring about the flame axis and having a diameter comparable to the maximum flame diameter. Closed- and open-tip flames were observed at small and large characteristic flame residence times, respectively, which supports earlier observations that open-tip behavior is caused by radiative quenching of soot oxidation near the flame tip.

2. Luminous flame lengths at laminar smoke-point conditions were equally well correlated for both closed-and open-tipped flame configurations in terms of a corrected fucl flow rate. independent of the jet exit diameter, as suggested by the simplified name shape analysis of Lin et al. [28]. These flame lengths were roughly $30 \%$ longer than flame lengths at laminar 
smoke-point conditions measured using ground-based microgravity facilities due to decreased effects of unsteadiness and g-jitter.

3. The present steady and nonbuoyant flames emitted soot more readily than other nonbuoyant flames at microgravity using ground-based facilities and buoyant flames at normal gravity. For example, the laminar smoke-point flame lengths of nonbuoyant flames from ground-based microgravity facilities were up to 2.3 times longer than the present measurements at comparable conditions due to effects of unsteadiness and g-jitter; similarly, the laminar smoke-point flame lengths of buoyant flames were up to 6.4 times longer than the present measurements at comparable conditions due to effects of buoyancy-induced motion.

4. Laminar smoke-point flame lengths as a function of pressure were identical for both closed-and open-tipped flames, and were roughly inversely proportional to pressure and relatively independent of jet exit diameter for the present nonbuoyant flames. In contrast, the laminar smoke-point flame lengths of nonbuoyant flames using ground-based microgravity facilities and buoyant flames at normal gravity were inversely proportional to pressure to the 1.4 and 1.3 power, respectively, due to effects of unsteadiness, g-jitter and buoyancy-induced motion. All flame conditions considered, however, indicited that laminar smoke-point flame 
lengths are generally smaller for ethylene than for propane, reflecting the greater propensity to soot of ethylene compared to propane.

\section{Nomenclature}

$\mathrm{C}_{\mathrm{f}} \quad$ flame length parameter

d fuel port diameter

D mass diffusivity

L laminar smoke-point flame length

$\dot{\mathrm{m}} \quad$ fuel mass flow rate

p pressure

$\operatorname{Re} \quad$ flame Reynolds number, $4 \dot{\mathrm{m}} /(\pi \mathrm{d} \mu)$

$\operatorname{Re}_{o} \quad$ jet exit Reynolds number, $4 \dot{\mathrm{m}} /\left(\pi \mathrm{d} \mu_{\mathrm{o}}\right)$

Sc Schmidt number, v/D

$t_{c h} \quad$ characteristic residence time, $2 \mathrm{~L} / \mathrm{u}_{\mathrm{o}}$

u streamwise velocity

$Z_{\mathrm{st}} \quad$ stoichiometric mixture fraction

$\mu \quad$ dynamic viscosity

$\checkmark \quad$ kinematic viscosity

$p \quad$ density

Subscript 
o burner exit condition

\section{Acknowledgments}

This research was supported by NASA Grants NCC3-661, NAG3-1878 and NAG32048 of the Office of Life and Microgravily Sciences.

\section{References}

1. Clarke, A.E., Hunter, T.C., and Garner, F.H., J. of Inst. Petrol. 32:627-642 (1946).

2. Schalla, R.L., Clark, T.P., and McDonald, G.E., NACA Report 1186, 1954.

3. Schalla, R.L., and McDonald, G.E., Fifth Symposium (International) on Combustion, The Combustion Institute, Pittsburgh, PA, 1954, p. 316-324.

4. Schalla, R. L., and Hubbard, R. R., NACA Report 1300, 1959.

5. Schug, K.P., Manheimer-Timnat, Y., Yaccarino, P., and Glassman, I., Combust. Sci. Tech. 22:235-250(1980).

6. Glassman, I., and Yaccarino, P., Eighteenth Symposium (International) on Combustion. The Combustion Institute, Pittsburgh, PA, 1980, pp. 1175-1183.

7. Glassman, I., and Yaccarino, P., Combust. Sci. Tech. 24:107-114 (1980).

8. Gomez, A., Sidebotham, G., and Glassman, I., Combust. Flame 58:45-57 (1984).

9. Glassman, I., Twenty-Second Symposium (International) on Combustion, The Combustion Institute, Pittsburgh, PA, 1988, pp. 295-311.

10. Glassman, I., Twenty-Seventh Symposium (International) on Combustion, The Combustion Institute, Pittsburgh, PA, 199S, pp. 1589-1596. 
11. Flower, W.L., and Bowman, C.T., Combust. Sci. Tech. 37:93-97 (1984).

12. Flower, W.L., and Bowman, C.T., Twentieth Symposium (International) on Combustion, The Combustion Institute, Pittsburgh, PA, 1984, pp. 1035-1129.

13. Flower, W.L., and Bowman, C.T., Twenty-First Symposium (International) on Combustion, The Combustion Institute, Pittsburgh, PA, 1986, pp. 1115-1129.

14. Flower, W.L., and Bowman, C.T., Combust. Sci. Tech. 53:217-224 (1987).

15. Markstein, G.H., Twenty-Second Symposium (International) on Combustion. The Combustion Institute, Pittsburgh, PA, 1988, pp. 363-370.

16. Sivathanu, Y.R., and Faeth, G.M., Combust. Flame 81:133-149 (1990).

17. Köylü, Ü.Ö., and Faeth, G.M., Combust. Flame 87:61-76 (1991).

18. Ito, H., Fujita, A., and Ito, K., Combust. Flame 99:363-370 (1994).

19. Ku, J.C., Griffin, D.W., Greenberg, P.S., and Roma, J., Combust. Flame 102:216-218 (1995).

20. Megaridis, C.M., Griffin, D.W., and Konsur, K., Twenty-Sixth Symposium (International) on Combustion, The Combustion Institute, Pittsburgh, PA, 1996, pp. 1291-1299.

21. Konsur, B., Megaridis, C.M., and Griffin, D.W., Combust. Flame 116:334-347 (1998).

22. Konsur, B., Megaridis, C.M., and Griffin, D.W., Combust. Flame 118:509-520 (1999).

23. Atreya, A., and Agrawal, S., Combust. Flame 115:372-382 (1998).

24. Sunderland, P.B., Mortazavi, S., Faeth, G.M., and Urban, D.L., Combust. Flame 96:97-103 (1994).

25. Urban, D.L., Yuan, Z.-G., Sunderland, P.B., Linteris, G.T., Voss, J.E., Lin, K.-C., Dai, Z., Sun, K., and Faeth, G.M., AIAA J. 36:1346-1360 (1998). 
26. Law, C.K., and Faeth, G.M., Prog. Energy Combust. Sci. 20:65-113 (1994).

27. Kang, K.T., Hwang, J.Y., Chung, S.M., and Lee, W., Combust. Flame 109:266-281 (1997).

28. Lin, K.-C., Faeth, G.M., Sunderland, P.B., Urban, D.L., and Yuan, Z.-G., Combust. Flame 116:415-431 (1998).

29. Spalding, D. B., Combustion and Mass Transfer, Pergamon Press, New York, 1979, pp. 185-195.

30. Sunderland, P.B., Mendelson, B.J., Yuan, Z.-G., and Urban, D.L., Combust. Flame 116:376-386 (1999). 


\section{List of Figures}

Fig. 1 Photographs of round nonbuoyant laminar jet diffusion flames in still air as the fuel flow rate is increased in the transition region where the laminar smoke-point is approached and exceeded for ethylene-fueled flames with a $1.6 \mathrm{~mm}$ jet exit diameter. Upper series of photographs are for open-tip smoke-point behavior at $100 \mathrm{kPa}$; lower series of photographs are for closed-tip smoke-point behavior at $50 \mathrm{kPa}$.

Fig. 2 Luminous flame lengths as a function of corrected fuel flow rate for round nonbuoyant laminar jet diffusion flames in still air at the laminar smoke-point. Correlation based on simplified analysis of Lin et al. [28].

Fig. 3 Laminar smoke-point flame lengths of ethylene-fueled round nonbuoyant and buoyant laminar jet diffusion flames burning in air as a function of pressure. Nonbuoyant KC-135 results from Sunderland et al. [24], buoyant results from Schug et al. [5] and Sivathanu and Faeth [16].

Fig. 4 Laminar smoke-point flame lengths of propane-fueled round nonbuoyant and buoyant laminar jet diffusion flames burning in air as a function of pressure. Nonbuoyant KC135 results from Sunderland et al. [24], buoyant results from Schug et al. [5] and Sivathanu and Faeth [16]. 

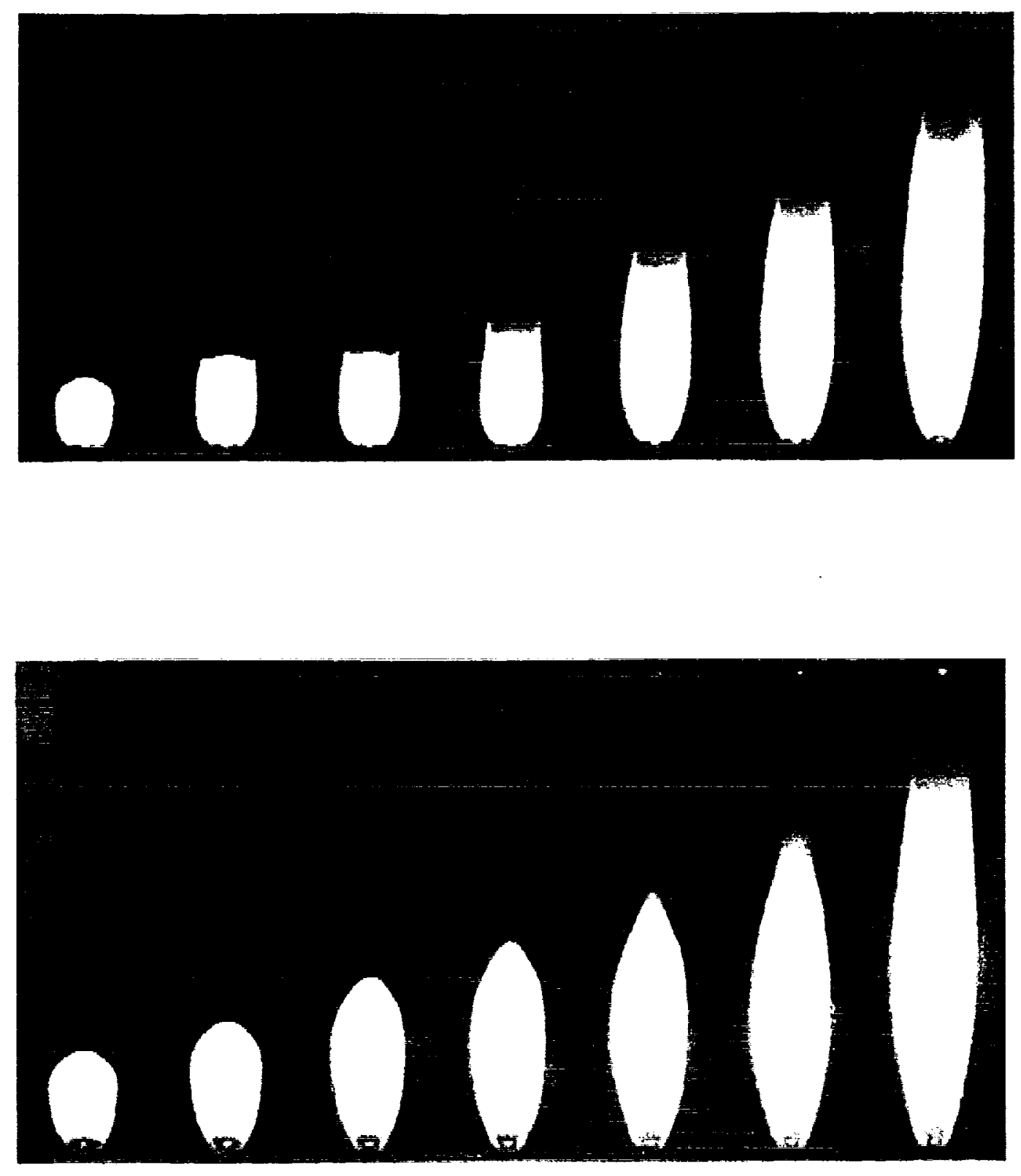

F(6) 


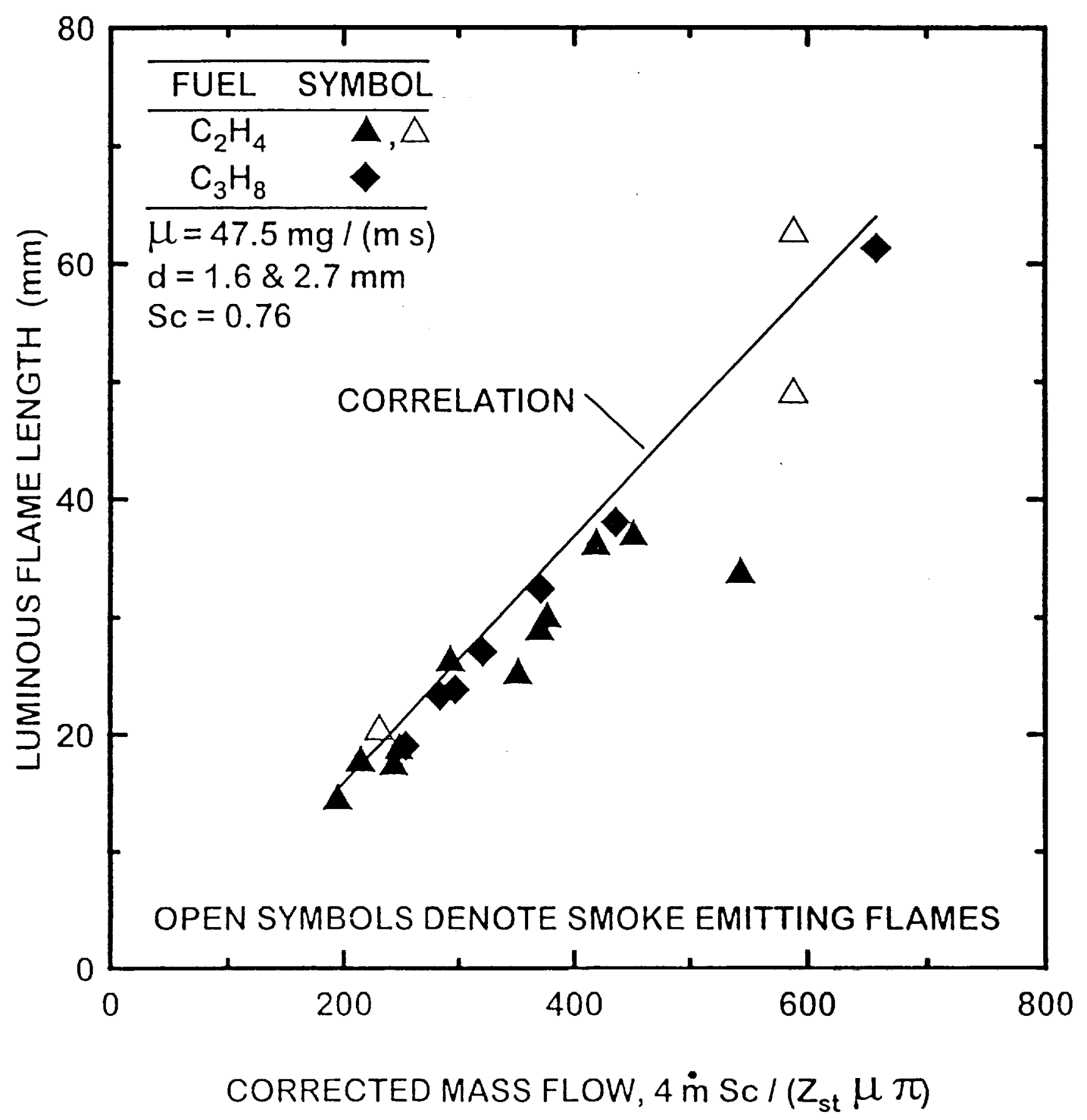




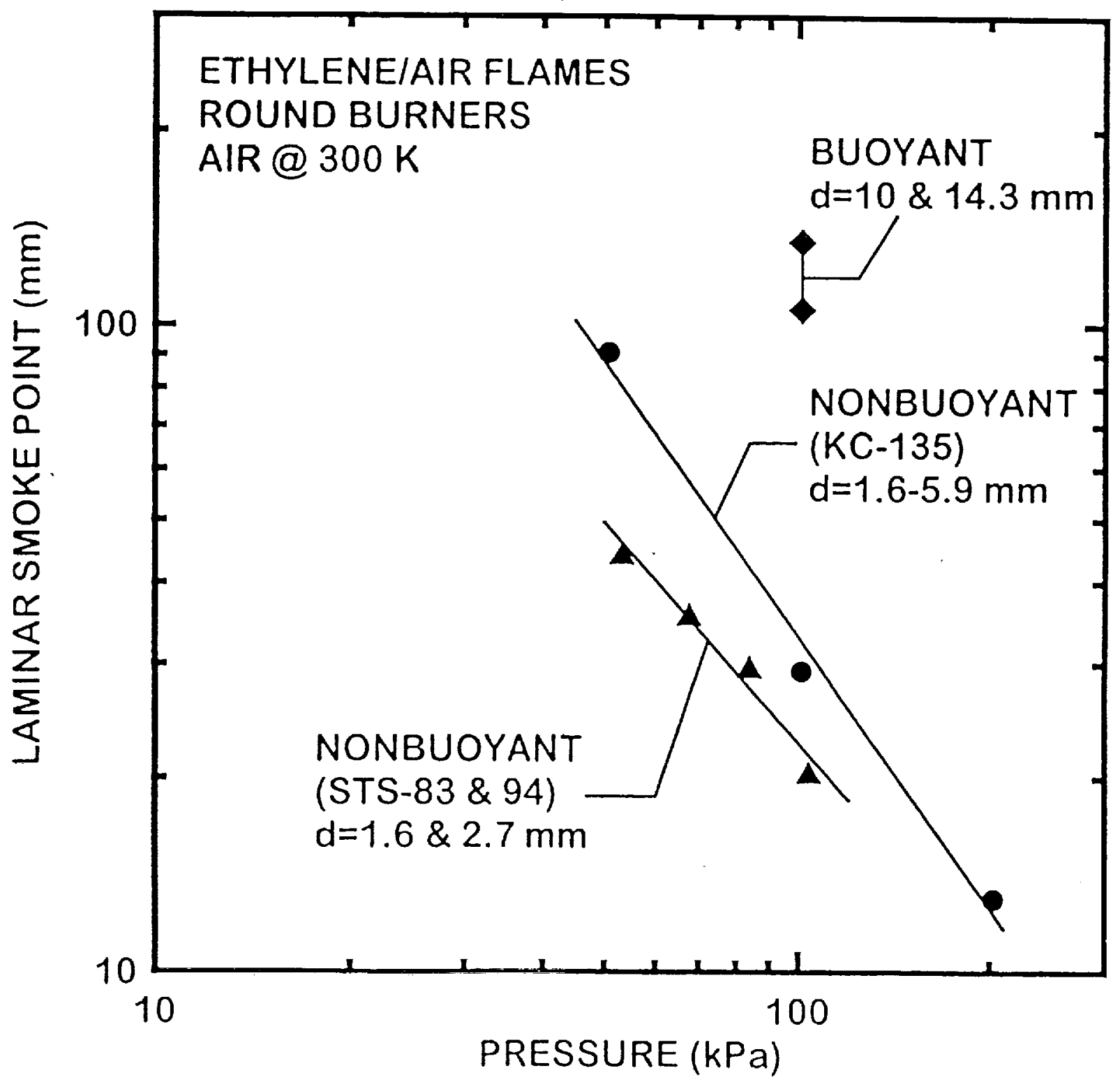

F/6.3 


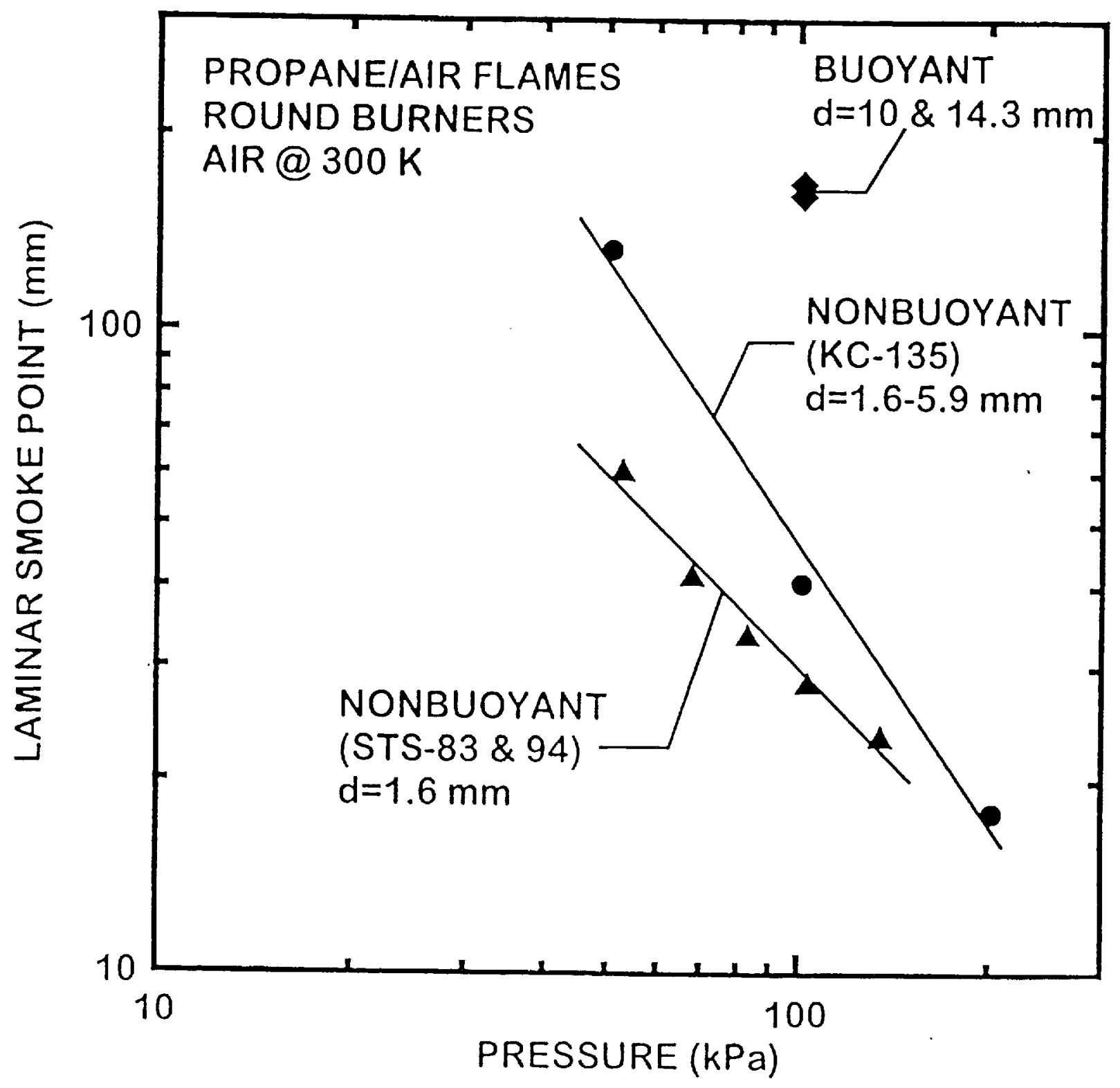

FIG.4. 
$\because$ 